\title{
P2Y2 receptor promotes cell invasion and metastasis in prostate cancer cells
}

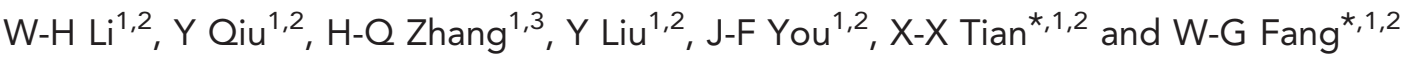 \\ ${ }^{1}$ Key Laboratory of Carcinogenesis and Translational Research, Ministry of Education, Peking University Health Science Center, \\ Beijing 100191, China; 'Department of Pathology, Peking University Health Science Center, Beijing 100191, China and \\ ${ }^{3}$ Department of Anatomy, Histology and Embryology, Peking University Health Science Center, Beijing 100191, China
}

Background: Our previous study demonstrated that extracellular adenosine $5^{\prime}$-triphosphate (ATP) stimulated prostate cancer cell invasion via P2Y receptors. However, the purinergic receptor subtype(s) involved in this process remains unclear. Here we aimed to determine whether P2Y2, one subtype of P2Y receptors, was involved in the invasion and metastasis of prostate cancer cells, and elucidated the underlying mechanism.

Methods: RNAi was introduced to silence the expression of P2Y2. In vitro invasion and migration assays and in vivo experiments were carried out to examine the role of P2Y2 receptor in cell invasion and metastasis. CDNA microarray was performed to identify the differentially expressed genes downstream of ATP treatment.

Results: P2Y2 was significantly expressed in the prostate cancer cells. Knockdown of P2Y2 receptor suppressed cell invasion and metastasis in vitro and in vivo. Further experiments identified that ATP could promote IL-8 and Snail expression and inhibit E-cadherin and Claudin-1 expression. Knockdown of P2Y2 receptor affected the expression of these EMT/invasion-related genes in vitro and in vivo.

Conclusion: P2Y2 receptor promotes cell invasion and metastasis in prostate cancer cells via some EMT/invasion-related genes. Thereby, P2Y2 receptor could be a potential therapeutic target for the treatment of prostate cancer.

Prostate cancer is the most common cancer in men in Western countries and a leading lethal tumour with increasing incidence worldwide (Papatsoris and Papavassiliou, 2001). Tumour invasion and metastasis remains the most lethal aspect of prostate cancer (Jaeger et al, 2001). Interactions between tumour cells and host organ microenvironments are required for tumour invasion and metastasis. Most of these interactions are now known to be receptor and ligand interactions (Cunha et al, 2003).

Extracellular adenosine $5^{\prime}$-triphosphate (ATP) interacts with purinergic receptors and mediates various biological functions in tumours, including cell proliferation, differentiation and death (Abbracchio and Burnstock, 1998). ATP acts via P2 receptors that are further divided into a P2Y family of G-proteincoupled receptors (P2Y1, 2, 4, 6, 11, 12, 13 and 14) and a $\mathrm{P} 2 \mathrm{X}$ family of ligand-gated ion channel receptors (P2X1-7)
(Von Kugelgen and Harden, 2011). Unlike P2X receptors, for which ATP is the unique ligand, a wide range of purine and pyrimidine nucleotides act as the ligands of $\mathrm{P} 2 \mathrm{Y}$ receptors. For $\mathrm{P} 2 \mathrm{Y} 1, \mathrm{P} 2 \mathrm{Y} 12$ and $\mathrm{P} 2 \mathrm{Y} 13$ receptors, the preferred ligand is ADP; for P2Y4, uridine $5^{\prime}$-triphosphate (UTP); for P2Y6, UDP; for P2Y11, ATP; and for P2Y14 are sugar nucleotides such as UDP-glucose and UDP-galactose; only for P2Y2 receptor, UTP and ATP are equally active (Di Virgilio, 2012).

Our previous study found that ATP could enhance in vitro invasion of human prostate cancer cells via P2Y receptors (Chen et al, 2004). However, the purinergic receptor subtype(s) involved in this process remains elusive. Different P2Y receptor subtypes have been identified in a variety of cancer types, in both primary samples of human cancer tissue and cell lines (Stagg and Smyth, 2010). As one of G-protein-coupled receptors, P2Y2 receptor can 
transactivate EGFR and increase mitogen-activated protein kinase and phosphoinositide 3-kinase activity in many cancer cells (Soltoff, 1998; Muscella et al, 2003). P2Y2 receptor exerts contrasting effects on cell proliferation of different cancers. It is reported that activation of $\mathrm{P} 2 \mathrm{Y} 2$ receptor can lead to an increase in cell growth in most types of cancer such as melanoma and lung tumours (Schafer et al, 2003; White et al, 2005). But in some other cancer types such as oesophageal cancer and colorectal cancer, activation of $\mathrm{P} 2 \mathrm{Y} 2$ receptor causes a decrease in cell proliferation (Hopfner et al, 2001; Maaser et al, 2002). Some studies have demonstrated that $\mathrm{P} 2 \mathrm{Y} 2$ receptor is overexpressed in colon cancer and pancreatic cancer (Kunzli et al, 2007; Nylund et al, 2007). However, the role of $\mathrm{P} 2 \mathrm{Y} 2$ receptor in tumour progression is still poorly understood. Therefore, in this study, we aimed to characterise the function of $\mathrm{P} 2 \mathrm{Y} 2$ receptor in the regulation of prostate cancer cell invasion and metastasis and tried to uncover the underlying mechanisms.

\section{MATERIALS AND METHODS}

Chemicals and antibodies. ATP and UTP were obtained from Sigma (St Louis, MO, USA). The antibodies of $\beta$-actin, E-cadherin and P2Y2 were obtained from Santa Cruz Biotechnology (Santa Cruz, CA, USA). Snail antibody and Claudin-1 antibody were purchased from Cell Signaling Technology (Danvers, MA, USA) and Zymed Laboratories Inc. (San Diego, CA, USA), respectively.

Cell lines and culture conditions. Two subclones 1E8 and 2B4 were derived from $\mathrm{PC}-3 \mathrm{M}$ human prostate carcinoma cell line. 1E8 was highly metastatic, whereas 2B4 was non-metastatic (Liu et al, 2001). Other cell lines were purchased from American Type Culture Collection (Manassas, VA, USA). All cells were cultured in RPMI 1640 (GIBCO, Grand Island, NY, USA) supplemented with $10 \%$ fetal bovine serum in a humidified atmosphere containing $5 \%$ $\mathrm{CO}_{2}$ at $37^{\circ} \mathrm{C}$.

RNAi and transfection. P2Y2 short interfering RNAs (siRNAs) were purchased from Invitrogen (Carlsbad, CA, USA). Two different P2Y2 siRNA oligonucleotides (siRNA1 and siRNA2) were used with the sequence as follows:

P2Y2 siRNA1, 5'-GUGCUAACAGUUGCCUUGA-3' and

P2Y2 siRNA2, 5'-GCCCAAGAGAUGAACAUCU- $3^{\prime}$.

A fluorescence-labelled oligonucleotide was used to directly observe siRNA transfection efficiency, and a scramble siRNA oligonucleotide was used as control siRNA (NC). 2B4 and 1E8 cells were transfected with siRNAs using Lipofectamine 2000 (Invitrogen). Twenty hours after transfection, cells were split. After an additional $12 \mathrm{~h}$, cells were treated with or without $100 \mu \mathrm{M}$ ATP and used for the following experiments.

P2Y2 shRNA was designed and purchased from Genepharma (Shanghai, China). Sequence targeting P2Y2 was inserted into pGPU6 RNAi plasmid to generate P2Y2 shRNA. A scramble sequence was inserted into pGPU6 RNAi plasmid and used as control shRNA (NC). Cells were transfected with the P2Y2 shRNA plasmid or control plasmid using Lipofectamine 2000 (Invitrogen). Stable transfected clones were selected by G418 (GIBCO).

In vitro invasion assay and migration assay. In vitro invasion assay was performed as described by Albini et al (1987), with some modifications. Briefly, the polycarbonate filter was coated with matrigel (BD, Franklin Lakes, NJ, USA) and incubated at $37^{\circ} \mathrm{C}$ for half an hour. The cells were harvested by typsinisation and suspended in RPMI 1640 with $0.1 \%$ BSA at $5 \times 10^{5}$ cells per ml. Two hundred microliter cell suspensions were placed in the upper chambers, and $600 \mu \mathrm{l} \mathrm{NIH3T3-conditioned} \mathrm{medium} \mathrm{was} \mathrm{filled} \mathrm{in}$ the lower chambers. The cells were treated with or without ATP and allowed to invade for $12 \mathrm{~h}$ at $37^{\circ} \mathrm{C}$. Then, the membranes were fixed with $4 \%$ formaldehyde, and cells on the lower surface of the membranes were stained with crystal violet. The invaded cells in seven fields were counted under the microscope at $\times 200$ magnification. Experiments were repeated at least three times, and data were presented as a percentage of the number of cells passing through filters in control.

In vitro migration assay was performed by using 24-well Transwell chambers (Costar, San Diego, CA, USA), which contained $6.5-\mathrm{mm}$ polycarbonate filters $(8-\mu \mathrm{m}$ pore size). The cells were prepared as described above. One million cells in $100 \mu \mathrm{l}$ of RPMI 1640 supplemented with $0.1 \%$ BSA was placed on the top of the chambers. Six hundred microliter NIH3T3-conditioned medium was added to the lower chamber. The cells were incubated for $12 \mathrm{~h}$ with or without ATP at $37^{\circ} \mathrm{C}$ in a humidified $5 \% \mathrm{CO}_{2}$ atmosphere incubator and then stained and quantified as mentioned in invasion assay.

Soft agar assay. Soft agar assay was performed to assess the effect of P2Y2 on anchorage-independent growth as follows. DMEM medium containing $0.6 \%$ agarose was poured into six-well culture plate to form the bottom layer. Cells with or without ATP treatment were suspended in DMEM containing 0.3\% agarose and plated as the top layer. Cells were plated in triplicate at the density of $0.8 \times 10^{3}$ cells per well. Colony numbers were counted after 14 days.

In vivo assay. For in vivo experiments, male $\mathrm{BALB} / \mathrm{c}$ nude mice at 4 weeks of age were obtained and maintained in a pathogen-free facility. All mice were handled according to the Guide for the Care and Use of Laboratory Animals. All experimental procedures and protocols were approved by the Institutional Animal Care and Use Committee of Peking University (no. LA2011-72). Cells from two 1E8 cell clones stably expressing P2Y2 shRNA (shRNA1 and shRNA2) and one stable clone expressing a control scramble shRNA (NC) were suspended in PBS at the concentration of $5 \times 10^{6}$ cells per $\mathrm{ml}$ and injected subcutaneously at the back of the mice ( $n=8$ for each group), respectively. Eight weeks after inoculation, mice were killed and dissected for collection of primary tumours and organs, including livers and lungs. The tumours were measured in volume. To identify the micrometastasis, livers and lungs of the mice were fixed in $4 \%$ paraformaldehyde and embedded in paraffin. Then the tissues were sectioned into $5 \mu \mathrm{m}$ slices. Every slice was stained with haematoxylin and eosin and viewed under a microscope with the Cellsens Standard software (Olympus, Shinjuku, Tokyo, Japan). To detect the expression of EMT/invasion-related genes in tumour tissues of mice, some tumour tissues were lysed with RIPA lysis buffer and the protein was extracted for western blotting and enzyme-linked immunosorbent assay (ELISA), and some tumour tissues were fixed in $4 \%$ paraformaldehyde, embedded in paraffin and sectioned into $5 \mu \mathrm{m}$ slices for immunofluorescence assay.

Immunofluorescence assay. After heated at $60{ }^{\circ} \mathrm{C}$ for $20 \mathrm{~min}$, the tumour tissue sections were deparaffinised in xylenes and rehydrated in graded ethanol. Then, antigen retrieval was performed in EDTA buffer ( $\mathrm{pH}$ 9.0). The sections were blocked for $30 \mathrm{~min}$ in a blocking solution (PBS, 5\% goat serum and $0.05 \%$ Tween-20) and incubated with primary antibodies at $4{ }^{\circ} \mathrm{C}$ overnight. Slides were washed and incubated with Alexa 594-conjugated or FITC-conjugated antibodies (Sigma) for $1 \mathrm{~h}$ at $37^{\circ} \mathrm{C}$. After stained with DAPI for $5 \mathrm{~min}$, the sections were observed with confocal microscopy.

cDNA microarray and data analyses. 2B4 and 1E8 cells were incubated with $100 \mu \mathrm{M}$ ATP or without ATP (controls) for 6 or $12 \mathrm{~h}$. Then poly (A) + mRNA was extracted from these cells and used to generate fluorescently labelled cDNA. According to the standard procedures, cDNA microarray was carried out on Human HT-12 v4 BeadChip (Illumina, San Diego, CA, USA), which 
contained $47231 \mathrm{cDNA}$ probes. After the BeadChips were scanned and analysed, data normalisation was performed using average algorithm. Gene expression in ATP-treated cells was compared against untreated cells at each time point. The Illumina Custom algorithm was used to identify significantly differentially expressed genes (detection of $P$-value $<0.01$ in each group and at least a 1.5 -fold variation at one or more time points). The differentially expressed genes were further classified through gene ontology analysis and pathway analysis by using Web-based Gene Set Analysis Toolkit (Zhang et al, 2005).

Reverse transcription and real-time PCR. Total RNA was extracted using Trizol reagent (Invitrogen), and $2 \mu \mathrm{g}$ of total RNA was reverse transcribed using M-MLV reverse transcriptase (Promega, Madison, WI, USA), according to the manufacturer's instructions. Because of no introns in the subtypes of P2Y receptors, DNase (Promega) was used to totally eliminate DNA contamination in the total RNA before reverse transcription. Realtime PCR was carried out using ABI StepOne Real-Time PCR System (Life Technologies, Carlsbad, CA, USA). Forward and reverse primers were listed in Supplementary Table 1. The expression of the examined genes was normalised by $\beta$-actin. Thermal cycle conditions were as follows: $10 \mathrm{~min}$ at $95^{\circ} \mathrm{C}$, and 40 cycles of $15 \mathrm{~s}$ at $95^{\circ} \mathrm{C}$ and $1 \mathrm{~min}$ at $60^{\circ} \mathrm{C}$. The $2^{-\Delta \Delta \mathrm{Ct}}$ method was used for relative quantification as described previously (Livak and Schmittgen, 2001; Zhang et al, 2010).

Cell lysis and western blotting. After rinsing with ice-cold PBS twice, cells were lysed in cell lysis buffer (PBS ( $\mathrm{pH} 7.4$ ), 1\% Triton $\mathrm{X}-100,10 \mathrm{~mm}$ sodium desoxycholate, $3 \mathrm{~mm}$ SDS and $1 \mathrm{~mm}$ EDTA with protease inhibitors). Protein concentrations were determined using a BCA protein assay. Then, equal amounts of protein were separated by SDS-PAGE under reducing conditions and transferred onto nitrocellulose membranes (Bio-Rad, Hercules, CA, USA). Blots were probed with E-cadherin $(1: 500)$, Snail $(1: 1000)$, Claudin-1 (1:1000), P2Y2 $(1: 500)$ and $\beta$-actin $(1: 1000)$, respectively. Immunoreactive bands were visualised by chemiluminescence (Applygen Technologies Inc, Beijing, China) and quantified by densitometry analysis using Quantity One software (Bio-Rad).

Enzyme-linked immunosorbent assay. Cells were grown on the 25-mm dishes, and the supernatant was collected from ATPtreated or untreated cells. After centrifuging at $10000 \mathrm{~g}$ for $10 \mathrm{~min}$ at $4{ }^{\circ} \mathrm{C}$, the supernatant was stored at $-80^{\circ} \mathrm{C}$ until assayed. IL- 8 protein level was measured using the Quantikine IL-8 ELISA Kit (Invitrogen), according to the manufacturer's instructions. The total protein concentration was then determined by absorbance comparison with the standard curve. Samples were assayed in duplicate, and the concentration of IL- 8 protein was normalised to total protein.

Statistical analyses. For all analysis, mean \pm s.d. of the measurements was calculated and illustrated in the histograms. Student's $t$-test was used to determine whether there was a significant difference between two means, and nonparametric ANOVA was performed for comparison of multiple means. Unless stated otherwise, all experiments were repeated at least three times. The data were analysed with the software package SPSS 19.0 (SPSS Inc., Chicago, IL, USA). Any $P$-value $\leqslant 0.05$ was considered statistically significant.

\section{RESULTS}

P2Y2 receptor is significantly expressed in prostate cancer cells. Prostate cancer cells express some of the P2Y receptor subtypes simultaneously (Janssens and Boeynaems, 2001). Previously, we demonstrated that P2Y receptors mediated extracellular ATP-enhanced in vitro invasion of prostate cancer (Chen et al, 2004). In this study, using real-time PCR, we found that 2B4, $1 \mathrm{E} 8$ and DU-145 cells predominantly expressed P2Y1 and P2Y2 mRNA (Figure 1A). The published data have shown that ATP and UTP are both preferred ligands for P2Y2 receptor (Di Virgilio, 2012), and here we found that extracellular UTP also enhanced invasion and migration of prostate cancer cells as ATP did (Supplementary Figure 1A-C), all of which indicated that P2Y2 receptor activation may be involved in the regulation of prostate cancer cell invasion and migration. Therefore, we focused our study on P2Y2 receptor. Using western blotting, we demonstrated that $\mathrm{P} 2 \mathrm{Y} 2$ protein was significantly expressed in all the examined prostate cancer cell lines (Figure 1B).

$\mathrm{P} 2 \mathrm{Y} 2$ receptor is involved in ATP-promoted invasion and migration of prostate cancer cells. To reveal the role of P2Y2 receptor in the ATP action, siRNA was designed to silence P2Y2 receptor in prostate cancer cells. Two different siRNAs (siRNA1 and siRNA2) were used, and each siRNA achieved prominent effect on knockdown of P2Y2 receptor in 2B4 and $1 \mathrm{E} 8$ cells (Figure 2A). ATP treatment increased the invasion
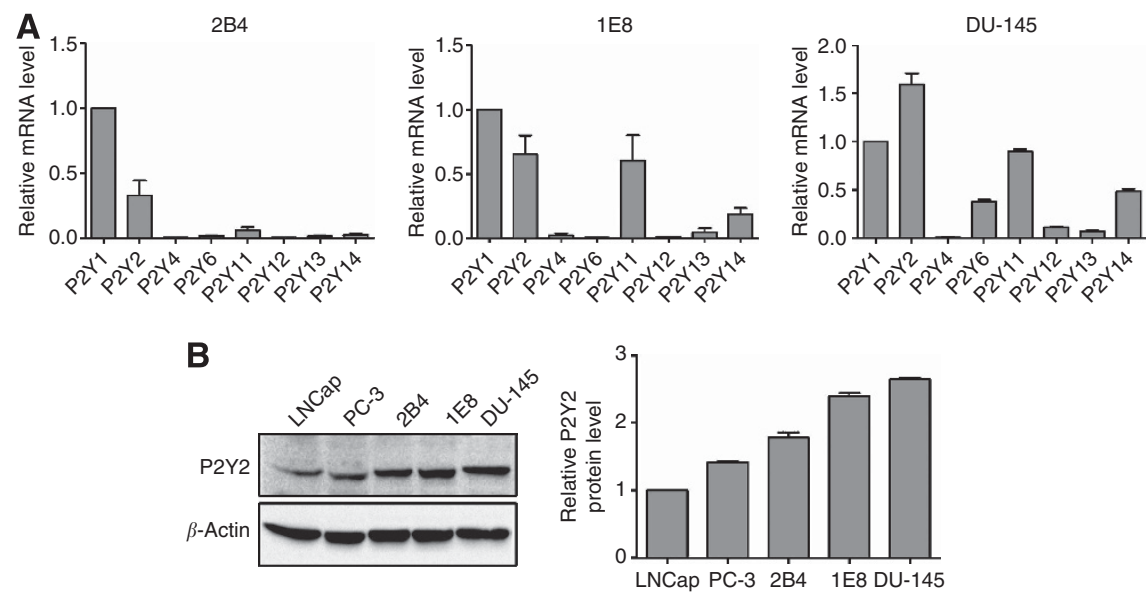

Figure 1. P2Y2 receptor was significantly expressed in prostate cancer cells. (A) mRNA levels of P2Y receptor subtypes were detected by real-time PCR in 2B4, 1E8 and DU-145 cells. The expressions of all P2Y receptor subtypes were normalised by $\beta$-actin, and mRNA expression of P2Y1 receptor was defined as 1. (B) Protein level of P2Y2 receptor was measured using western blot analysis in prostate cancer cell lines. Results were demonstrated by histograms to quantify the expression levels. Data were presented as mean \pm s.d. (vertical bars). Three independent experiments were performed. 
A

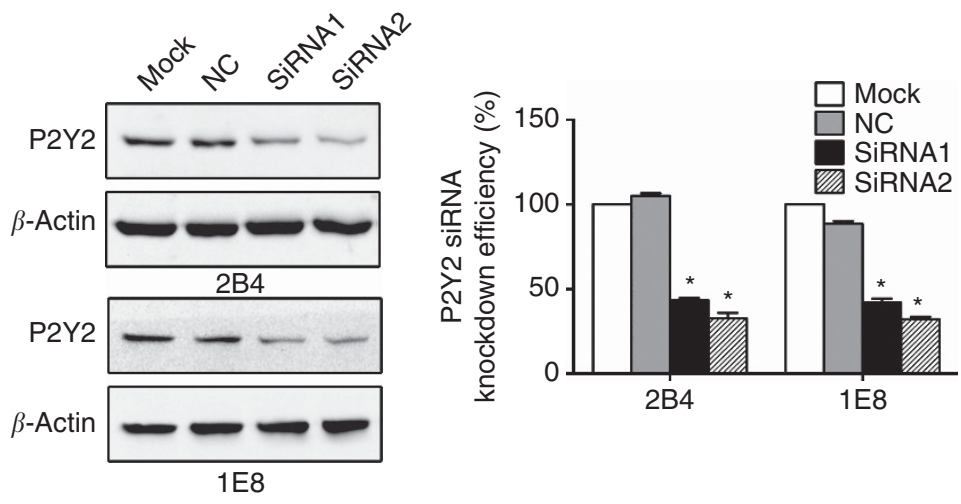

B
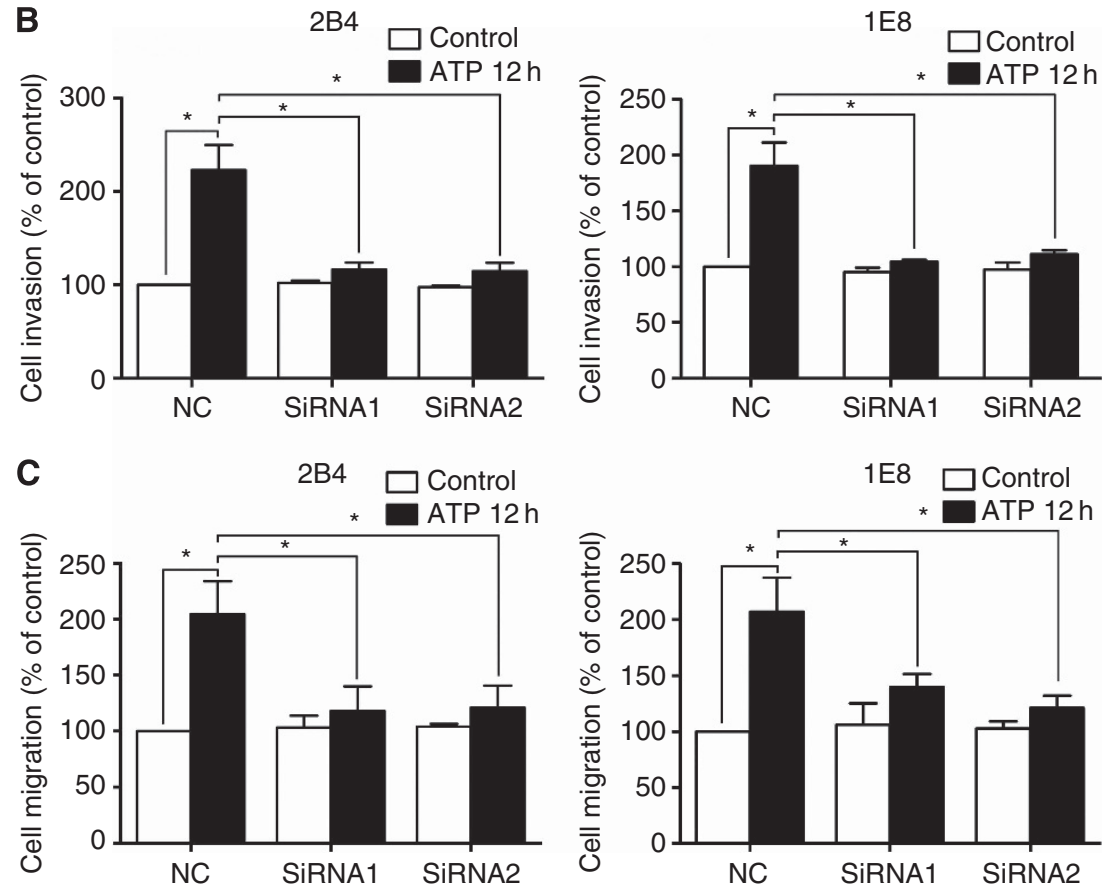

Figure 2. Effects of P2Y2 receptor knockdown on ATP-mediated in vitro invasion and migration. (A) 2B4 and 1E8 cells were transfected with two different P2Y2 siRNAs (siRNA1 and siRNA2) or a control siRNA (NC). Western blotting was used to evaluate the knockdown efficiency. (B) Effect of P2Y2 receptor knockdown on in vitro invasion after incubation with ATP for $12 \mathrm{~h}$. (C) Effect of P2Y2 receptor knockdown on in vitro migration after incubation with ATP for $12 \mathrm{~h}$. Results were demonstrated by histograms and data were presented as mean $\pm \mathrm{s} . \mathrm{d}$. (vertical bars).

Three independent experiments were performed. ${ }^{*} P<0.05$.

and migration of prostate cancer cells in control siRNA cells. After knockdown of $\mathrm{P} 2 \mathrm{Y} 2$ receptor, this effect was significantly inhibited, suggesting the involvement of $\mathrm{P} 2 \mathrm{Y} 2$ receptor in the ATP-promoted invasion and migration of prostate cancer cells (Figure $2 \mathrm{~B}$ and $\mathrm{C}$ ).

P2Y2 receptor participates in invasion and metastasis of prostate cancer cells in vivo. Next, we analysed the effect of $\mathrm{P} 2 \mathrm{Y} 2$ receptor on invasion and metastasis in vivo. Two $1 \mathrm{E} 8$ clones stably expressing P2Y2 shRNA (shRNA1 and shRNA2) were shown to express low levels of $\mathrm{P} 2 \mathrm{Y} 2$ protein using western blotting, and one stable clone expressing a control scramble shRNA (NC) demonstrated similar level of P2Y2 protein as parental cells (Figure 3A). These stable clones were used in the following experiments. Tumours in mice that were injected with control cells invaded into the neighbouring tissues, including the fat tissue (Figure 3Di) and muscle (Figure 3Dii). However, tumours in mice injected with P2Y2-silenced cells did not display apparent invasion (Figure 3Diii-vi). Moreover, 50\% of mice that were injected with control cells exhibited obviously liver metastasis, whereas mice receiving $\mathrm{P} 2 \mathrm{Y} 2$-silenced cells did not show liver metastasis (Figure 3E and F). Silencing of P2Y2 receptor in 1E8 cells resulted in decreased tumour growth in nude mice compared with control cells (Figure $3 \mathrm{~B}$ and $\mathrm{C}$ ), which is thought to be mainly due to decreased anchorage-independent growth as shown by soft agar assay (Supplementary Figure 2).

Extracellular ATP and UTP regulated EMT/invasion-related gene expression in prostate cancer cells. Previously, we demonstrated that extracellular ATP could enhance invasion of prostate cancer cells (Chen et al, 2004). To identify the invasion/metastasisrelated genes downstream of ATP treatment, we performed a comparative gene expression analysis using cDNA microarray technology in 2B4 and 1E8 cells (Figure 4A). Interestingly, we found that ATP could regulate the expression of IL-8, Snail, E-cadherin and Claudin-1, which had significant roles in EMT and metastasis. The result was further validated in 2B4, $1 \mathrm{E} 8$ and DU-145 cells. Real-time PCR and ELISA assay both showed that the expression of IL-8 was upregulated after ATP treatment (Figure $4 \mathrm{~B}$ and C). The expression of some EMT-related genes also 
A

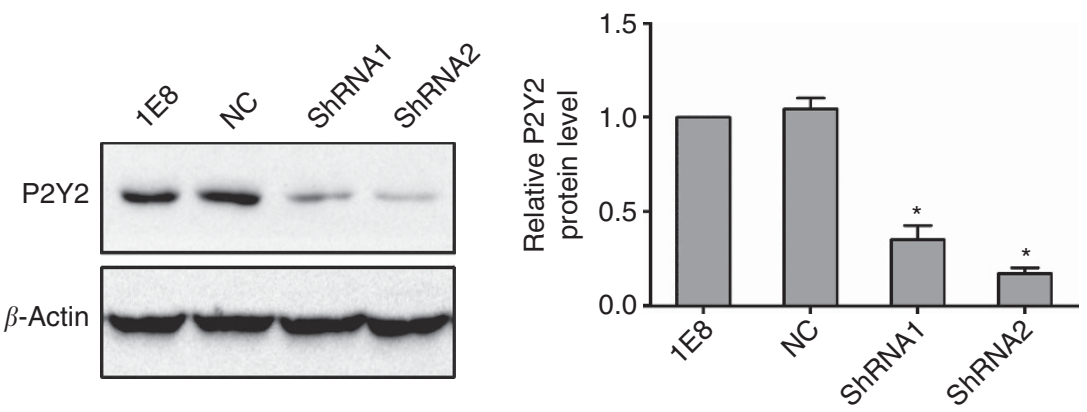

B
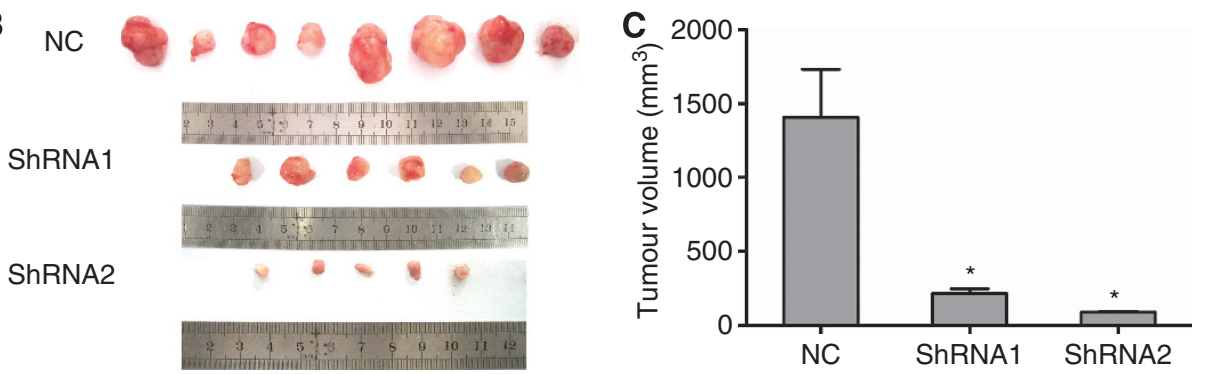

D

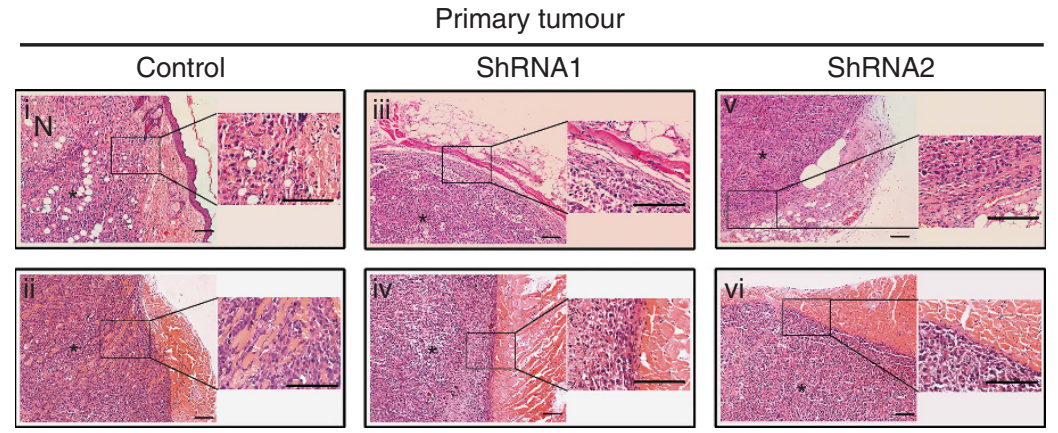

E

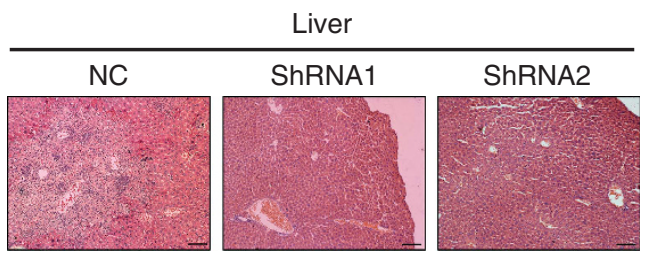

$\mathbf{F}$

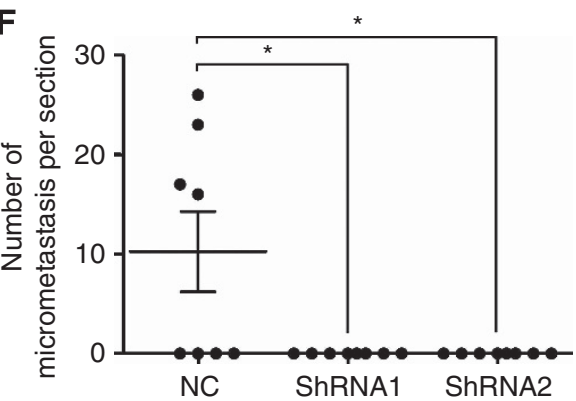

Figure 3. Silencing of P2Y2 inhibited the invasion and metastasis of prostate cancer cells in vivo. (A) $1 \mathrm{E} 8$ cells were stably transfected with $\mathrm{P} 2 \mathrm{Y} 2$ shRNA or a scramble shRNA (NC). Two stable P2Y2 shRNA clones (shRNA1 and shRNA2) were shown to express low levels of P2Y2 using western blot analysis. ${ }^{*} P<0.05$. (B) Representative photograph of the tumours in BABL/c nude mice injected with control cells or P2Y2-silenced cells. (C) Tumour volume was measured and shown by a histogram. ${ }^{*} P<0.05$. (D) Representative photograph of tumour sections and adjacent tissues (stained with haematoxylin and eosin (HE)). ${ }^{*}$, tumour mass; N, necrosis; Scale bars $=100 \mu \mathrm{m}$. (E) Representative photographs of liver section (stained with HE) from tumour-bearing mice. Scale bars $=100 \mu \mathrm{m}$. (F) The production of liver metastasis and number of micrometastasis per section in tumour-bearing mice. ${ }^{\star} P<0.05$.

showed significant changes after ATP treatment, including increased expression of Snail (Figure 4D and E) and decreased expression of E-cadherin (Figure $4 \mathrm{~F}$ and $\mathrm{G}$ ) and Claudin-1 (Supplementary Figure 3A, only significant at $12 \mathrm{~h}$ treatment), which indicated that ATP could induce EMT in prostate cancer cells. Consistent with ATP, UTP exerts similar effects on the regulation of IL-8, Snail, E-cadherin and Claudin-1 expression at both the mRNA and protein levels (Supplementary Figures 3B and 4). These results imply that activation of $\mathrm{P} 2 \mathrm{Y} 2$ receptor may have a major role in mediating the expression of EMT/invasion-related genes.
P2Y2 receptor mediated the expression of EMT/invasion-related genes in vitro and in vivo. Using ELISA assay, we found that ATP treatment significantly increased the expression of IL-8 in control siRNA cells. But in P2Y2-silenced cells, this effect was significantly attenuated (Figure 5A). Furthermore, after knockdown of P2Y2 receptor, ATP-mediated increase of Snail expression (Figure 5B), as well as decrease of E-cadherin (Figure 5C) and Claudin-1 expression (Supplementary Figure 5), was suppressed. These data support the notion that $\mathrm{P} 2 \mathrm{Y} 2$ receptor is required for the ATP-mediated expression changes of EMT/invasion-related genes in prostate cancer cells. 

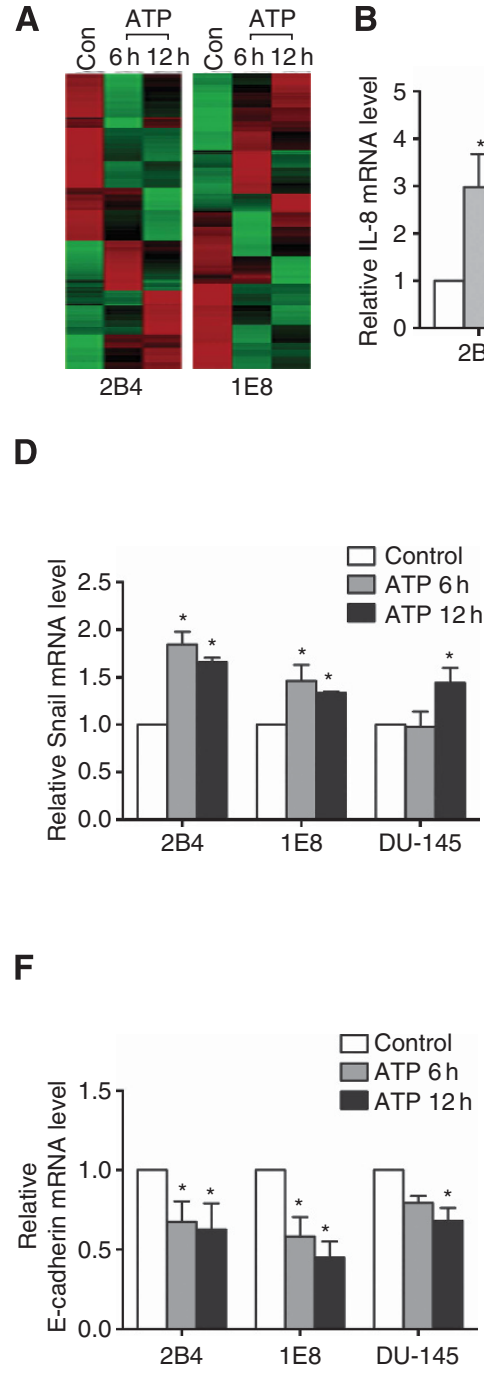
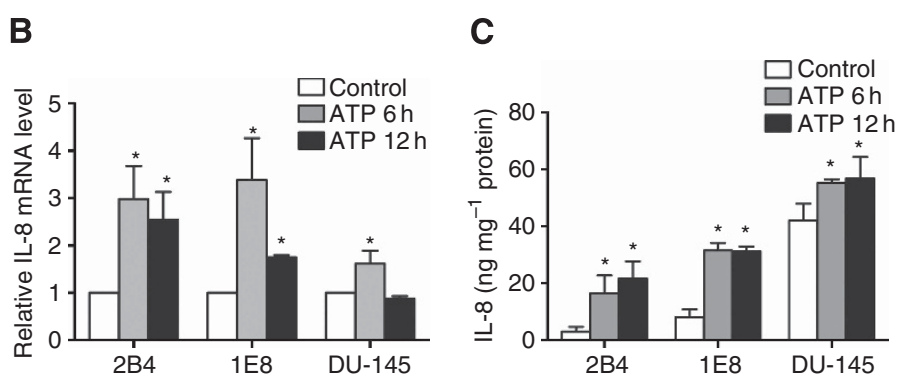

$\mathbf{E}$
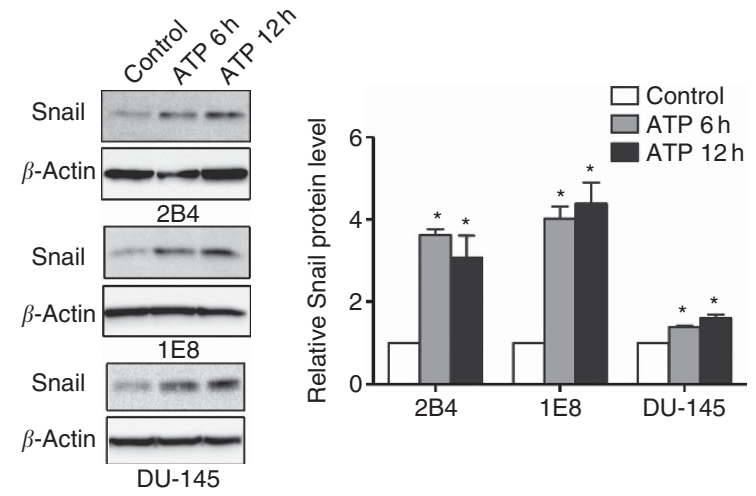

G

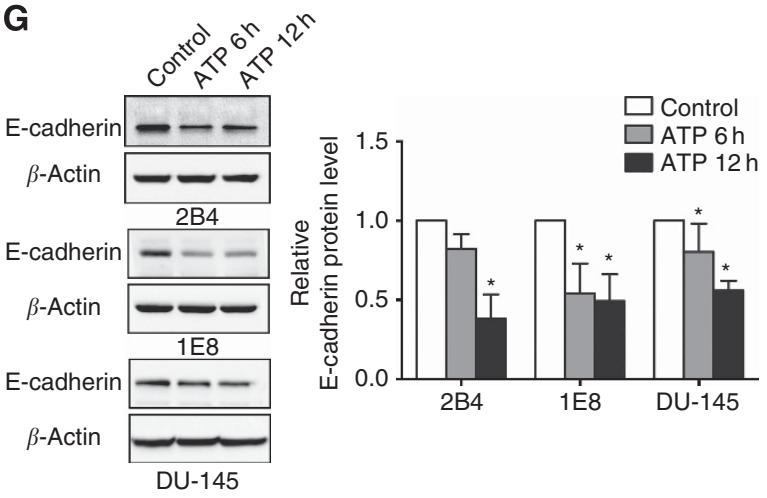

Figure 4. Extracellular ATP regulated the expression of IL-8, Snail and E-cadherin in prostate cancer cells. (A) cDNA microarray analysis was performed in 2B4 and 1E8 cells after incubated with $100 \mu \mathrm{m}$ ATP for 6 or $12 \mathrm{~h}$. Heat maps that were generated from cDNA microarray represented differentially expressed genes between ATP-treated and untreated cells (red, upregulated; green, downregulated). (B) Expression of IL-8 mRNA was detected by real-time PCR after incubation with ATP for 6 and $12 \mathrm{~h}$. (C) Expression of IL-8 protein was detected by ELISA assay after ATP treatment for 6 and $12 \mathrm{~h}$. Real-time PCR and western blotting were used to observe changes of EMT-related genes $(\mathbf{D}, \mathbf{E})$ Snail and $(\mathbf{F}, \mathbf{G})$ E-cadherin. Results were demonstrated by histograms to quantify the expression levels. Data were presented as mean \pm s.d. (vertical bars). Three independent experiments were performed. ${ }^{*} P<0.05$ vs control cells.

Then, we examined the expressions of Snail, E-cadherin, Claudin- 1 and IL- 8 in the primary tumours of mice formed by $1 \mathrm{E} 8$ control shRNA cells and P2Y2 shRNA cells. The result showed that after knockdown of P2Y2 receptor, the expression of Snail and IL-8 was decreased, whereas the level of E-cadherin and Claudin-1 was increased in the tumour tissues, suggesting that $\mathrm{P} 2 \mathrm{Y} 2$ receptor regulated the expression of EMT/invasion-related genes in vivo (Figure 6A-C).

\section{DISCUSSION}

There were early reports of the beneficial effect of ATP in the treatment of cancer (Rapaport, 1983; Fang et al, 1992). However, high concentration of ATP, in hundreds micromolar range, can be observed at tumour sites in vivo, whereas it is basically undetectable in healthy tissues, indicating that ATP may act as a stimulus in the cancer progression (Pellegatti et al, 2008). Recent studies have found that extracellular ATP can increase the migration of C6 glioma cells and promote the invasion of breast cancer cells (Jantaratnotai and Mclarnon, 2011; Jelassi et al, 2011). Our previous study revealed that extracellular ATP enhanced invasion of prostate cancer cells via $\mathrm{P} 2 \mathrm{Y}$ receptors (Chen et al, 2004; Zhang et al, 2010). In this study, we proved that knockdown of $\mathrm{P} 2 \mathrm{Y} 2$ receptor repressed ATP-promoted invasion and migration in vitro and suppressed in vivo invasion and metastasis of prostate cancer cells. Using cDNA microarray, we identified that ATP could increase the expression of IL- 8 and Snail, as well as decrease the expression of E-cadherin and Claudin-1. Knockdown of P2Y2 receptor attenuated ATP-regulated expression changes of EMT/ invasion-related genes. In addition, knockdown of P2Y2 receptor affected the expression of these EMT/invasion-related genes in vivo. Although multiple ATP receptor subtypes are ubiquitously 

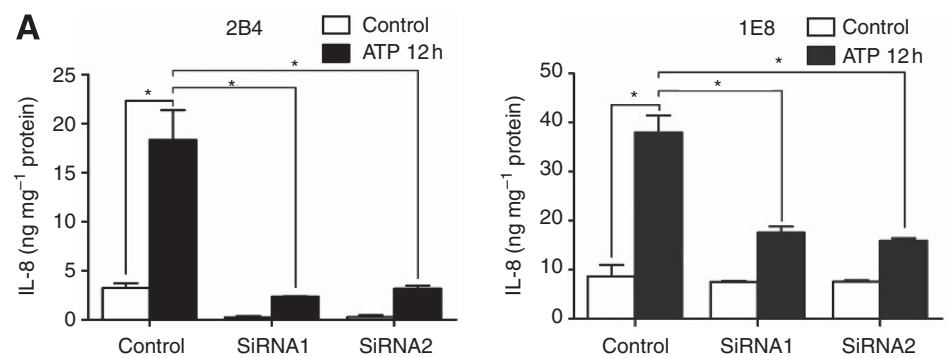

B
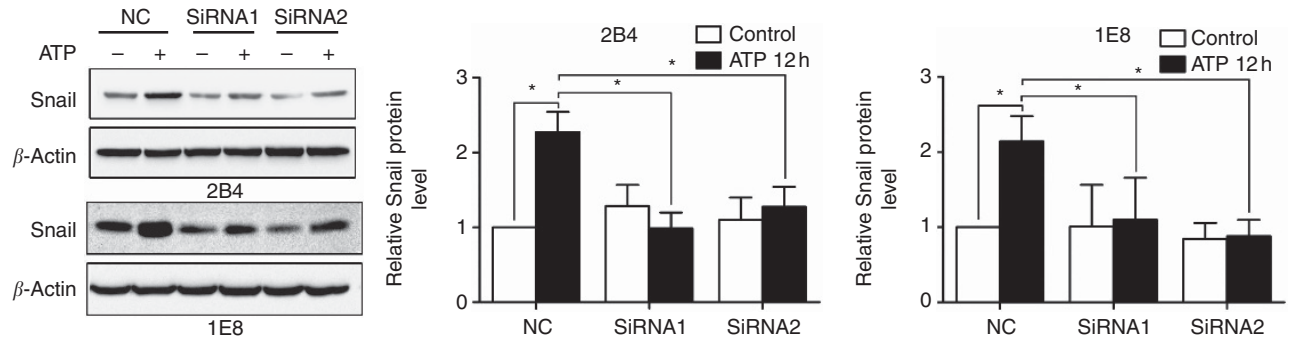

C
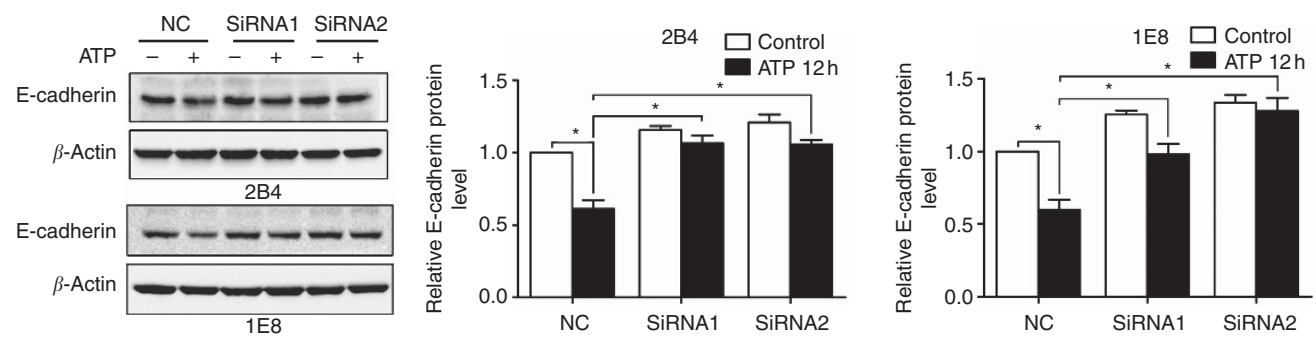

Figure 5. P2Y2 receptor was involved in the ATP-mediated expression of IL-8, Snail and E-cadherin in prostate cancer cells. (A) P2Y2-silenced cells and control cells were treated with $100 \mu \mathrm{M}$ ATP for $12 \mathrm{~h}$, and cell supernatant was collected for IL-8 protein examination by ELISA assay. Cells were treated with $100 \mu \mathrm{m}$ ATP for $12 \mathrm{~h}$, and western blotting was performed to detect the expression of (B) Snail and (C) E-cadherin. Results were demonstrated by histograms to quantify the expression levels. Data were presented as mean \pm s.d. (vertical bars). Three independent experiments were performed. ${ }^{*} P<0.05$

expressed in prostate cancer cells, and the contribution of other ATP receptor subtype(s) cannot be fully excluded, our data strongly suggest that $\mathrm{P} 2 \mathrm{Y} 2$ receptor is the major factor in mediating the invasion and metastasis of prostate cancer cells.

Eight P2Y receptor subtypes have been identified in mammalian cells. Among P2Y receptor subtypes (P2Y1, 2, 4, 6, 11, 12, 13 and 14), $\mathrm{P} 2 \mathrm{Y} 2$ receptor is overexpressed in colon cancer and pancreatic cancer and acts as an oncogene in the carcinogenesis of colorectal cancer (Hatanaka et al, 2007; Kunzli et al, 2007; Nylund et al, 2007). Using real-time PCR and western blotting, we found that $\mathrm{P} 2 \mathrm{Y} 2$ was significantly expressed in all the examined prostate cancer cells. Some studies have shown that P2Y2 receptor is involved in neutrophil chemotaxis and mediate the migration of astrocytoma cells (Bagchi et al, 2005; Chen et al, 2006). In this study, we demonstrated that knockdown of P2Y2 receptor suppressed the ATP-promoted invasion and migration of prostate cancer cells, indicating that activation of $\mathrm{P} 2 \mathrm{Y} 2$ receptor could promote the invasion and migration of prostate cancer cells. Our results are also consistent with other studies that P2Y2 receptor has a strong transforming potential in vitro and in vivo (Hatanaka et al, 2007). P2Y2 receptor has been reported to participate in the metastasis of colorectal cancer cells in mice model (Kunzli et al, 2011). In this study, complementary with the in vitro data, we found that silencing of $\mathrm{P} 2 \mathrm{Y} 2$ suppressed the invasion and metastasis of prostate cancer cells in vivo, further confirming the involvement of $\mathrm{P} 2 \mathrm{Y} 2$ receptor in the regulation of prostate cancer cell invasion and metastasis.
Tumour-derived IL- 8 exerts profound effects on tumour cell behaviour in tumour microenvironment, and increased IL-8 levels are known to promote tumour metastasis in several kinds of cancers including prostate, breast and ovarian cancers (Inoue et al, 2000; Lin et al, 2004; Shahzad et al, 2010). It has been reported that extracellular ATP induces the expression of IL-8 through P2 receptors in eosinophils, and IL-8-induced neutrophil chemotaxis requires a concurrent activation of $\mathrm{P} 2$ receptors (Idzko et al, 2003; Kukulski et al, 2009). However, little study focuses on the effect of ATP on IL-8 expression in cancer cells. In our experiments, using real-time PCR and ELISA assay, we proved that IL- 8 secretion in prostate cancer cells was increased after activation of P2Y2 receptor by ATP or UTP. Using siRNA technology, we confirmed that P2Y2 was the crucial receptor in the regulation of ATPmediated expression increase of IL-8. Furthermore, we identified that $\mathrm{P} 2 \mathrm{Y} 2$ receptor regulated IL-8 expression in vivo.

EMT is now thought to have a fundamental role in tumour progression and metastasis formation (Christiansen and Rajasekaran, 2006). During EMT, proteins that promote cell-cell adherence such as E-cadherin and Claudin-1 can be decreased. These proteins are regulated by a family of zinc finger regulatory protein like Snail and Slug (Steeg, 2006). ATP has been shown to participate in the EGF-induced EMT process in breast cancer cells (Davis et al, 2011). In our study, we found that activation of P2Y2 receptor by ATP or UTP could upregulate the expression of Snail and downregulate the expression of E-cadherin and Claudin-1 at mRNA and protein levels in vitro. After knockdown of P2Y2 

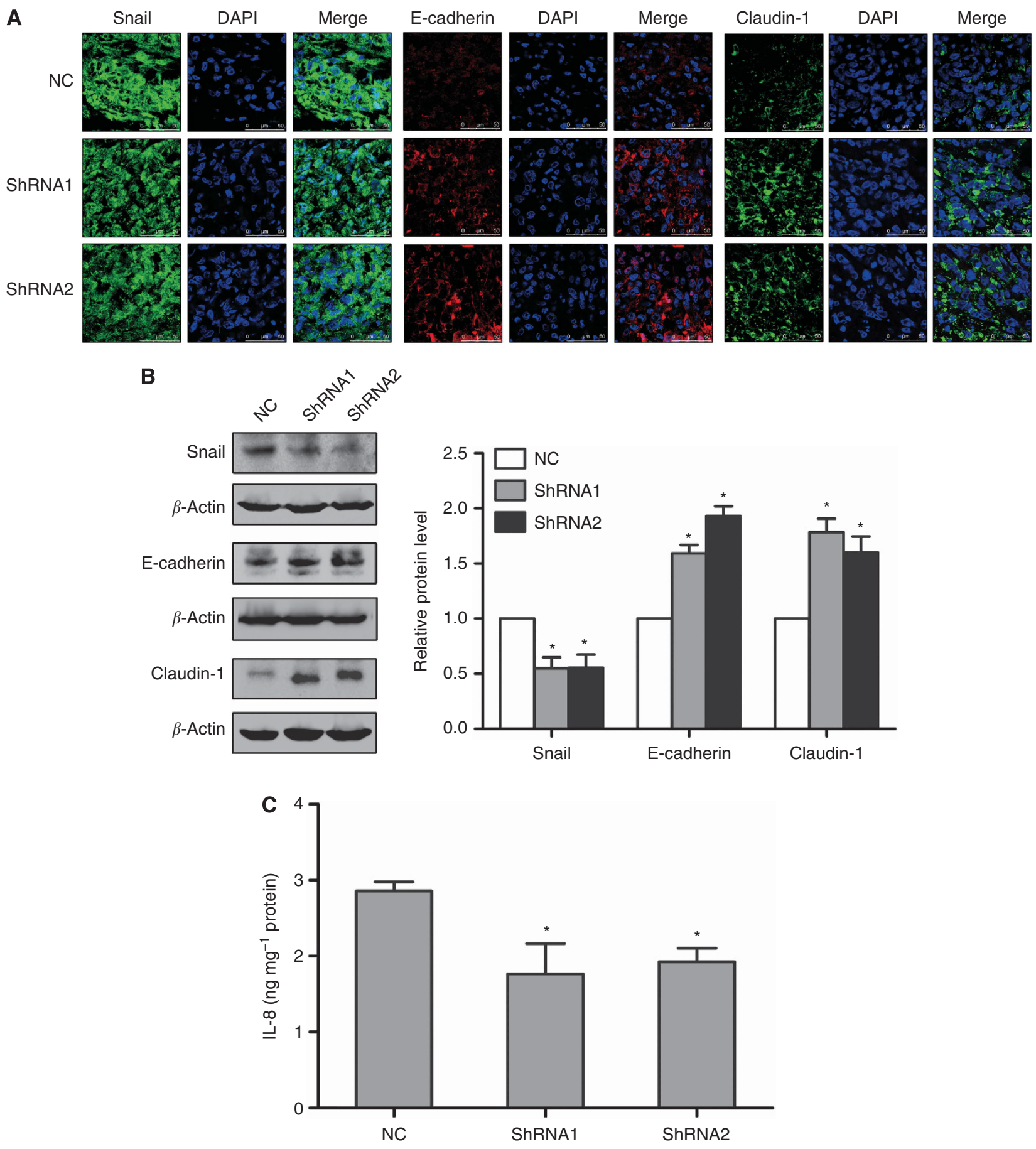

Figure 6. Silencing of P2Y2 receptor affected the expression of Snail, E-cadherin, Claudin-1 and IL-8 in tumour tissues of mice. (A) The protein levels of Snail, E-cadherin and Claudin-1 in tumour tissues was examined by immunofluorescence assay. After staining with Snail, E-cadherin or Claudin-1 antibodies, cells were further stained with DAPI. Immunofluorescent images were taken with the confocal microscope. (B) The protein levels of Snail, E-cadherin and Claudin-1 in tumour tissues were detected using western blotting. (C) IL-8 expression in tumour tissues was examined by ELISA assay. Three separate tumours from three mice were used in the experiments. ${ }^{\star} P<0.05$ vs NC tumours.

receptor, the expression changes of ATP-induced EMT-related genes were inhibited. We also found that knockdown of P2Y2 receptor decreased the expression of Snail and increased the level of E-cadherin and Claudin-1 in the tumour tissues of mice. These data implied that activation of P2Y2 receptor could induce EMT. Some reports have proved that extracellular ATP stimulation increases free cytosolic calcium in tumours such as prostate and breast cancers (Fang et al, 1992; Davis et al, 2012). Calcium signal is critical in the cancer progression, and recent study identifies that calcium signal is required for the induction of EMT (Davis et al, 2013). Therefore, it is possible that activation of P2Y2 receptor induces EMT via the calcium signalling pathway.

Claudin-1 is a tight junction protein, and it is involved in cellular signalling affecting proliferation, motility and invasion (Turksen and Troy, 2011). Reduced Claudin-1 expression was shown to correlate with poor differentiation, acquisition of a metastatic phenotype and poor patient survival in colorectal cancer (Resnick et al, 2005). However, overexpression of Claudin-1 in 
normal liver cells induced EMT through activation of the c-AblERK signalling pathway, and thus demonstrated a pivotal role in hepatocellular carcinoma metastasis (Suh et al, 2012). The role of Claudin-1 in prostate cancer is not clear. Activation of P2Y2 receptor induced downregulation of Claudin-1 in prostate cancer, probably through upregulation of Snail, because it has been shown that Snail may downregulate the expression of Claudin-1 (Wu and Zhou, 2010).

In summary, our in vitro data analysis demonstrated that knockdown of P2Y2 receptor inhibited the ATP-promoted invasion and migration of prostate cancer cells and attenuated extracellular ATP-mediated expression changes of EMT/invasionrelated genes. Our in vivo experiment also showed that knockdown of P2Y2 receptor could suppress invasion and metastasis of prostate cancer cells and affect the expression of EMT/invasionrelated genes. Taken together, our study indicated that P2Y2 receptor promotes cell invasion and metastasis in prostate cancer cells. Thus, P2Y2 receptor may act as a therapeutic target for the treatment of prostate cancer.

\section{ACKNOWLEDGEMENTS}

This work was supported by grants to WGF from National Natural Science Foundation of China (30971152) and 973 Program (2010CB529402) from the Ministry of Science and Technology of China.

\section{CONFLICT OF INTEREST}

The authors declare no conflict of interest.

\section{REFERENCES}

Abbracchio MP, Burnstock G (1998) Purinergic signalling: pathophysiological roles. Jpn J Pharmacol 78(2): 113-145.

Albini A, Iwamoto Y, Kleinman HK, Martin GR, Aaronson SA, Kozlowski JM, Mcewan RN (1987) A rapid in vitro assay for quantitating the invasive potential of tumor cells. Cancer Res 47(12): 3239-3245.

Bagchi S, Liao Z, Gonzalez FA, Chorna NE, Seye CI, Weisman GA, Erb L (2005) The P2Y2 nucleotide receptor interacts with alphav integrins to activate Go and induce cell migration. J Biol Chem 280(47): 39050-39057.

Chen L, He HY, Li HM, Zheng J, Heng WJ, You JF, Fang WG (2004) ERK1/2 and $\mathrm{p} 38$ pathways are required for $\mathrm{P} 2 \mathrm{Y}$ receptor-mediated prostate cancer invasion. Cancer Lett 215(2): 239-247.

Chen Y, Corriden R, Inoue Y, Yip L, Hashiguchi N, Zinkernagel A, Nizet V, Insel PA, Junger WG (2006) ATP release guides neutrophil chemotaxis via P2Y2 and A3 receptors. Science 314(5806): 1792-1795.

Christiansen JJ, Rajasekaran AK (2006) Reassessing epithelial to mesenchymal transition as a prerequisite for carcinoma invasion and metastasis. Cancer Res 66(17): 8319-8326.

Cunha GR, Hayward SW, Wang YZ, Ricke WA (2003) Role of the stromal microenvironment in carcinogenesis of the prostate. Int J Cancer 107(1): $1-10$.

Davis FM, Azimi I, Faville RA, Peters AA, Jalink K, Putney Jr JW, Goodhill GJ, Thompson EW, Roberts-Thomson SJ, Monteith GR (2013) Induction of epithelial-mesenchymal transition (EMT) in breast cancer cells is calcium signal dependent. Oncogene; e-pub ahead of print 20 May 2013; doi:10.1038/ onc.2013.187.

Davis FM, Kenny PA, Soo ET, Van Denderen BJ, Thompson EW, Cabot PJ, Parat MO, Roberts-Thomson SJ, Monteith GR (2011) Remodeling of purinergic receptor-mediated $\mathrm{Ca} 2+$ signaling as a consequence of EGFinduced epithelial-mesenchymal transition in breast cancer cells. PLoS One 6(8): e23464.

Davis FM, Peters AA, Grice DM, Cabot PJ, Parat MO, Roberts-Thomson SJ, Monteith GR (2012) Non-stimulated, agonist-stimulated and storeoperated $\mathrm{Ca}^{2+}$ influx in MDA-MB-468 breast cancer cells and the effect of EGF-induced EMT on calcium entry. PLoS One 7(5): e36923.
Di Virgilio F (2012) Purines, purinergic receptors, and cancer. Cancer Res 72(21): 5441-5447.

Fang WG, Pirnia F, Bang YJ, Myers CE, Trepel JB (1992) P2-purinergic receptor agonists inhibit the growth of androgen-independent prostate carcinoma cells. J Clin Invest 89(1): 191-196.

Hatanaka H, Takada S, Choi YL, Fujiwara S, Soda M, Enomoto M, Kurashina K, Watanabe H, Yamashita Y, Sugano K, Mano H (2007) Transforming activity of purinergic receptor P2Y, G-protein coupled, 2 revealed by retroviral expression screening. Biochem Biophys Res Commun 356(3): 723-726.

Hopfner M, Maaser K, Barthel B, Von Lampe B, Hanski C, Riecken EO, Zeitz M, Scherubl H (2001) Growth inhibition and apoptosis induced by P2Y2 receptors in human colorectal carcinoma cells: involvement of intracellular calcium and cyclic adenosine monophosphate. Int J Colorectal Dis 16(3): 154-166.

Idzko M, Panther E, Bremer HC, Sorichter S, Luttmann W, Virchow Jr CJ, Di Virgilio F, Herouy Y, Norgauer J, Ferrari D (2003) Stimulation of P2 purinergic receptors induces the release of eosinophil cationic protein and interleukin-8 from human eosinophils. Br J Pharmacol 138(7): 1244-1250.

Inoue K, Slaton JW, Eve BY, Kim SJ, Perrotte P, Balbay MD, Yano S, Bar-Eli M, Radinsky R, Pettaway CA, Dinney CP (2000) Interleukin 8 expression regulates tumorigenicity and metastases in androgenindependent prostate cancer. Clin Cancer Res 6(5): 2104-2119.

Jaeger EB, Samant RS, Rinker-Schaeffer CW (2001) Metastasis suppression in prostate cancer. Cancer Metastasis Rev 20(3-4): 279-286.

Janssens R, Boeynaems JM (2001) Effects of extracellular nucleotides and nucleosides on prostate carcinoma cells. Br J Pharmacol 132(2): 536-546.

Jantaratnotai N, Mclarnon JG (2011) Calcium dependence of purinergic subtype P2Y(1) receptor modulation of C6 glioma cell migration. Neurosci Lett 497(2): 80-84.

Jelassi B, Chantome A, Alcaraz-Perez F, Baroja-Mazo A, Cayuela ML, Pelegrin P, Surprenant A, Roger S (2011) P2X(7) receptor activation enhances SK3 channels- and cystein cathepsin-dependent cancer cells invasiveness. Oncogene 30(18): 2108-2122.

Kukulski F, Ben Yebdri F, Lecka J, Kauffenstein G, Levesque SA, Martin-Satue M, Sevigny J (2009) Extracellular ATP and P2 receptors are required for IL-8 to induce neutrophil migration. Cytokine 46(2): 166-170.

Kunzli BM, Berberat PO, Giese T, Csizmadia E, Kaczmarek E, Baker C, Halaceli I, Buchler MW, Friess H, Robson SC (2007) Upregulation of CD39/NTPDases and P2 receptors in human pancreatic disease. Am J Physiol Gastrointest Liver Physiol 292(1): G223-G230.

Kunzli BM, Bernlochner MI, Rath S, Kaser S, Csizmadia E, Enjyoji K, Cowan P, D'apice A, Dwyer K, Rosenberg R, Perren A, Friess H, Maurer CA, Robson SC (2011) Impact of CD39 and purinergic signalling on the growth and metastasis of colorectal cancer. Purinergic Signal 7(2): 231-241.

Lin Y, Huang RC, Chen LP, Li SY, Shi Q, Jordan C, Huang RP (2004) Identification of interleukin-8 as estrogen receptor-regulated factor involved in breast cancer invasion and angiogenesis by protein arrays. Int J Cancer 109(4): 507-515.

Liu Y, Zheng J, Fang W, You J, Wang J, Cui X, Wu B (2001) Identification of metastasis associated gene G3BP by differential display in human cancer cell sublines with different metastatic potentials G3BP as highly expressed in non-metastatic. Chin Med J (Engl) 114(1): 35-38.

Livak KJ, Schmittgen TD (2001) Analysis of relative gene expression data using real-time quantitative PCR and the 2(T)(-Delta Delta C) method. Methods 25(4): 402-408.

Maaser K, Hopfner M, Kap H, Sutter AP, Barthel B, Von Lampe B, Zeitz M, Scherubl H (2002) Extracellular nucleotides inhibit growth of human oesophageal cancer cells via P2Y(2)-receptors. Br J Cancer 86(4): 636-644.

Muscella A, Elia MG, Greco S, Storelli C, Marsigliante S (2003) Activation of $\mathrm{P} 2 \mathrm{Y} 2$ receptor induces c-FOS protein through a pathway involving mitogen-activated protein kinases and phosphoinositide 3-kinases in HeLa cells. J Cell Physiol 195(2): 234-240.

Nylund G, Hultman L, Nordgren S, Delbro DS (2007) P2Y2- and P2Y4 purinergic receptors are over-expressed in human colon cancer. Auton Autacoid Pharmacol 27(2): 79-84.

Papatsoris AG, Papavassiliou AG (2001) Prostate cancer: horizons in the development of novel anti-cancer strategies. Curr Med Chem Anticancer Agents 1(1): 47-70.

Pellegatti P, Raffaghello L, Bianchi G, Piccardi F, Pistoia V, Di Virgilio F (2008) Increased level of extracellular ATP at tumor sites: in vivo imaging with plasma membrane luciferase. PLoS One 3(7): e2599. 
Rapaport E (1983) Treatment of human tumor cells with ADP or ATP yields arrest of growth in the S phase of the cell cycle. J Cell Physiol 114(3): 279-283.

Resnick MB, Konkin T, Routhier J, Sabo E, Pricolo VE (2005) Claudin-1 is a strong prognostic indicator in stage II colonic cancer: a tissue microarray study. Mod Pathol 18(4): 511-518.

Schafer R, Sedehizade F, Welte T, Reiser G (2003) ATP- and UTP-activated P2Y receptors differently regulate proliferation of human lung epithelial tumor cells. Am J Physiol Lung Cell Mol Physiol 285(2): L376-L385.

Shahzad MMK, Arevalo JM, Armaiz-Pena GN, Lu C, Stone RL, Moreno-Smith M, Nishimura M, Lee J-W, Jennings NB, Bottsford-Miller J, Vivas-Mejia P, Lutgendorf SK, Lopez-Berestein G, Bar-Eli M, Cole SW, Sood AK (2010) Stress Effects on FosB- and Interleukin-8 (IL8)-driven Ovarian Cancer Growth and Metastasis. J Biol Chem 285(46): 35462-35470.

Soltoff SP (1998) Related adhesion focal tyrosine kinase and the epidermal growth factor receptor mediate the stimulation of mitogen-activated protein kinase by the G-protein-coupled P2Y2 receptor. Phorbol ester or $[\mathrm{Ca} 2+] \mathrm{i}$ elevation can substitute for receptor activation. J Biol Chem 273(36): 23110-23117.

Stagg J, Smyth MJ (2010) Extracellular adenosine triphosphate and adenosine in cancer. Oncogene 29(39): 5346-5358.

Steeg PS (2006) Tumor metastasis: mechanistic insights and clinical challenges. Nat Med 12(8): 895-904.

Suh Y, Yoon CH, Kim RK, Lim EJ, Oh YS, Hwang SG, An S, Yoon G, Gye MC, Yi JM, Kim MJ, Lee SJ (2012) Claudin-1 induces epithelial-mesenchymal transition through activation of the c-Abl-ERK signaling pathway in human liver cells. Oncogene; e-pub ahead of print 3 June 2013; doi:10.1038/ onc.2012.205.

Turksen K, Troy TC (2011) Junctions gone bad: claudins and loss of the barrier in cancer. Biochim Biophys Acta 1816(1): 73-79.

Von Kugelgen I, Harden TK (2011) Molecular pharmacology, physiology, and structure of the P2Y receptors. Adv Pharmacol 61: 373-415.

White N, Ryten M, Clayton E, Butler P, Burnstock G (2005) P2Y purinergic receptors regulate the growth of human melanomas. Cancer Lett 224(1): 81-91.

Wu Y, Zhou BP (2010) TNF-alpha/NF-kappaB/Snail pathway in cancer cell migration and invasion. Br J Cancer 102(4): 639-644.

Zhang B, Kirov S, Snoddy J (2005) WebGestalt: an integrated system for exploring gene sets in various biological contexts. Nucleic Acids Res 33(Web Server issue): W741-W748.

Zhang Y, Gong LH, Zhang HQ, Du Q, You JF, Tian XX, Fang WG (2010) Extracellular ATP enhances in vitro invasion of prostate cancer cells by activating Rho GTPase and upregulating MMPs expression. Cancer Lett 293(2): 189-197.

This work is published under the standard license to publish agreement. After 12 months the work will become freely available and the license terms will switch to a Creative Commons AttributionNonCommercial-Share Alike 3.0 Unported License.

Supplementary Information accompanies this paper on British Journal of Cancer website (http://www.nature.com/bjc) 